\title{
Nanostructured Zinc Oxide for Water Treatment
}

\author{
Sunandan Baruah ${ }^{1}$ Samir K. Pal ${ }^{2}$ and Joydeep Dutta ${ }^{3, *}$
}

${ }^{1}$ Assam Don Bosco University, Airport Road, Azara, Guwahati 781017, India; ${ }^{2}$ Department of Chemical, Biological and Macromolecular Sciences, S. N. Bose National Centre for Basic Sciences, Block JD, Sector III, Salt Lake, Kolkata 700 098, India; ${ }^{3}$ Chair in Nanotechnology for Water Desalination and other applications, Water Research Center, Sultan Qaboos University, P. O. Box 17, Al-Khoudh123, Sultanate of Oman

\begin{abstract}
Environmental pollution and industrialization on a global scale have drawn attention to the vital need for developing new hygienically friendly purification technologies. Existing wastewater treatment technologies demand high capital investment and operation \& maintenance cost, and large area. Cost-effective treatment of pollutants requires the transformation of hazardous substances into benign forms and the subsequent development of effective risk management strategies from harmful effects of pollutants that are highly toxic, persistent, and difficult to treat. Application of nanotechnology that results in improved water treatment options might include removal of the finest contaminants from water $(<300 \mathrm{~nm})$ and "smart materials" or "reactive surface coatings" with engineered specificity to a certain pollutant that destroy, transform or immobilize toxic compounds. Nanomaterials have been gaining increasing interest in the area of environmental remediation mainly due to their enhanced surface and also other specific changes in their physical, chemical and biological properties that develop due to size effects. Heterogeneous photocatalytic systems via metal oxide semiconductors like $\mathrm{TiO}_{2}$ and $\mathrm{ZnO}$, are capable of operating effectively and efficiently for waste water treatment which has been discussed along with other nanotechnology routes that can be useful for water treatments. Multifunctional photocatalytic membranes using $\mathrm{ZnO}$ nanostructures are considered advantageous over freely suspended nanoparticles due to the ease of its removal from the purified water. A short discussion on the study of charge transfer mechanisms during photocatalytic reactions has also been included.
\end{abstract}

Keywords: Contamination, photocatalysis, metal oxide, purification.

\section{INTRODUCTION}

Many of the current world problems like high chemical contamination in air, water and soil including high carbon compounds, are related to this fast pace of population growth. Current world population is about 6.5 billion and increasing at an alarming rate and is projected to be 9 million by 2050 [1] Efforts to tackle the population related issues has resulted in severe damage to the ecosystem thereby creating health hazards through environmental pollution. Increased demand for more habitation led to large-scale deforestation and decreased agricultural land, lowering the yield. The production level of food grains is of concern as it has been showing a downward trend over the last decade. Further, extensive use of persistent chemical pesticides to boost agriculture production has also adversely affected our ecosystem and is known to have contaminated ground water [2, 3]. Similarly, industrialization is leading to increase in per capita consumption of available natural resources. Out of 1,386 million cubic kilometers $\left(\mathrm{km}^{3}\right)$ of water on Earth, $97 \%$ is saline and $99.7 \%$ of the freshwater is trapped in ice caps and glaciers, or found in groundwater (one third). Only about 0.1 million $\mathrm{km}^{3}$ of water is above ground in lakes, swamps and rivers, and about $13,000 \mathrm{~km}^{3}$ in the atmosphere [4].

*Address correspondence to this author at the Chair in Nanotechnology for Water Desalination and other applications, Water Research Center, Sultan Qaboos University, P. O. Box 17, Al-Khoudh123, Sultanate of Oman; Tel: +968-24143266; Fax: +968-24413532; E-mail: dutta@squ.edu.om
Surface water has not increased for the past 20 years, and simultaneously, groundwater tables have been dropping [5].

Water is a fundamental requirement for life. The availability of fresh water is crucial for life sustaining activities like drinking, cooking, cleaning, agriculture, etc. Nature has its own mechanism for water recycling to provide us with adequate quantity of fresh water with consumable purity level. Modern human activities have however disrupted the balance between the usage and natural purification processes leading to a shortage of potable water. Most of the natural resources of drinking water are found to be contaminated with diverse toxic materials and pathogenic microorganisms [2] 700 million people across the globe face water scarcity, and it is estimated that this problem will touch 1.8 billion people by 2025 [6]. According to a World Health Organization (WHO) report, water borne diseases kill nearly 12 million people every year [7]. About $90 \%$ of all diseases occurring in developing countries are related to the consumption of impure water leading to nearly 4 billion reported cases of diseases contracted from water in the world [8]. Worldwide, there are nearly 4 billion reported cases of diseases contracted from water. 'Low carbon water' through artificial methods has therefore become a necessity for the survival of the human race.

Disinfection of drinking water is currently being carried out through physical and chemical techniques like chlorination, ozonation, UV treatment, etc. Each of the conventional water disinfection processes has limitations 
generating concerns about their mass scale application $[2,3,9,10]$. Advanced nanotechnology offers unprecedented opportunities for progress - defeating poverty, starvation and disease and expanding human capacities. Nanotechnology is defined as the ability to understand, control, and manipulate matter at the level of individual atoms and molecules, as well as at the "supramolecular" level involving clusters of molecules (in the range of about 0.1 to $100 \mathrm{~nm}$ ), in order to create materials, devices, and systems with fundamentally new properties and functions because of their small structure [11]. Application of nanotechnology that results in improved waste treatment options might include removal of the finest contaminants from water $(<300 \mathrm{~nm})$ and "smart" materials or reactive surface coatings with induced specificity to a certain pollutant that destroy or immobilize toxic compounds and pathogens.

Heterogeneous photocatalysis is currently being considered as a promising technique for water purification in comparison to other conventional methods $[2,3]$ as it can break up complex long chained organic molecules (normally toxic) into simpler fragments as well as distort cell walls of microbes thereby immobilizing them. Nanotechnology offers lot of promise in the area of water purification owing to large surface to volume ratios offered by nanostructures [12] and the possibility of preparing photocatalytic membranes by growing semiconducting nanostructures on conventional membranes $[13,14]$. The use of renewable energy like solar energy in place of fossil fuels can offer an efficient and clean way of water purification in remote locations. A major advantage of the use of antimicrobial nanomaterial like silver (Ag), zinc oxide $(\mathrm{ZnO})$, etc. in water purification is the prospect of developing point-of-use systems [15]. The concept of decentralized water treatment systems is being considered due to deterioration of water quality in old distribution networks and the ever-increasing transportation costs. The importance of membranes in drinking water and waste water treatment systems is gaining importance [16].
Integration of antimicrobial or photocatalytic nanomaterials makes the membranes functional, achieving multiple treatment goals in a single process while minimizing fouling [15]. Attachment of nanomaterials to supports is crucial to minimize loss of nanomaterials, and also to avoid potential impacts of nanomaterials on human health and ecosystems $[17,18]$.

\section{PHOTOCATALYSIS FOR WATER DECONTAMINA- TION}

Photocatalysis, using nanostructures of metal oxide semiconductors like zinc oxide $(\mathrm{ZnO})$, titania $\left(\mathrm{TiO}_{2}\right)$, tungsten oxide $\left(\mathrm{WO}_{3}\right)$, zinc stannate $\left(\mathrm{Zn}_{2} \mathrm{SnO}_{4}\right)$, etc. can be an attractive way of water purification as it is capable of removing chemical as well as biological contaminants [19-23]. A good photocatalyst should absorb light efficiently preferably in the visible or near UV part of the electromagnetic spectrum. Sufficient electron vacant states need to be present to inhibit recombination of electron hole pairs upon light exposure. Photocatalysis applications in the agriculture and microbiology are gaining wide spread acceptance and it is important that the photocatalysts should be biologically inert and non-toxic. Nanostructured photocatalysts offer large surface to volume ratios allowing higher adsorption of the target molecules. Intensive research over the past decade for its implementation in the purification of drinking water can be found in the literature [2, 24-41]. Efficacy of photocatalysis, in the detoxification of a wide range of industrial and agricultural effluents is also well documented [42]. Another interesting aspect of photocataysis is the potential utilization of sunlight, which could allow energy efficient treatment in remote locations.

The underlying mechanism of heterogeneous photocatalysis is schematically represented in Fig. (1). It involves a wide band gap semiconductor photocatalyst, which upon irradiation with light of energy higher than the band gap energy of the material, electron-hole pairs (excitons) are

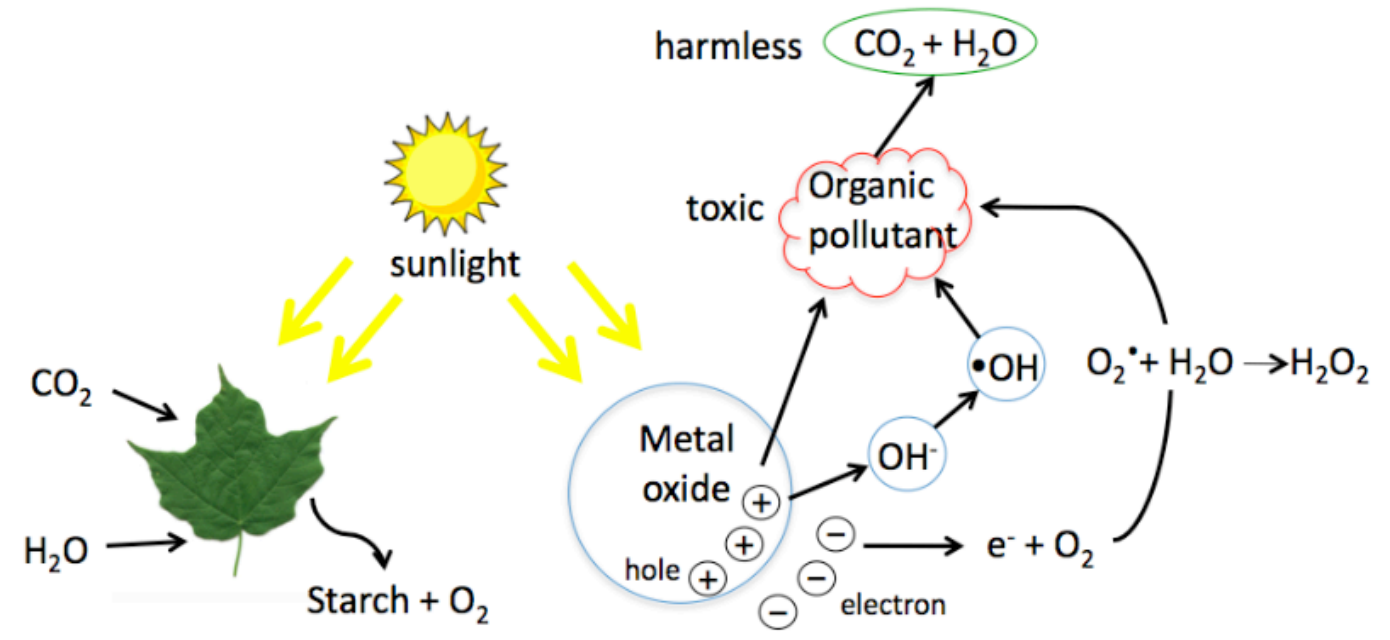

\section{Photosynthesis}

\section{Photocatalysis}

Fig. (1). Comparison of photosynthesis process in leaves and photocatalysis using metal oxide nanoparticles. In photocatalytic process energy more than the optical bandgap of the semiconductors are generally required (compared to $2.5 \mathrm{eV}$ for photosynthesis process). 
created. The photogenerated electron moves up to the conduction band while the hole drifts to the bottom of the valence band. Majority of these photogenerated charge carriers undergo wasteful recombination, while escape recombination and initiate redox reactions in molecules adsorbed at the surface of the photocatalyst and thereby degrading them. The photogenerated electrons and holes have been found to degrade almost all types of organic, inorganic, and microbial contaminants [42], owing to their high redox potentials. by

The fundamental process during photocatalysis is given

$\mathrm{MO}+h v \rightarrow \mathrm{MO}\left(\mathrm{e}^{-}+\mathrm{h}^{+}\right)$

where MO represents a metal oxide photocatalyst like $\mathrm{TiO}_{2}$, $\mathrm{ZnO}$ etc. Photo-generated electrons lead to the formation of superoxide anions $\left({ }^{\bullet} \mathrm{O}_{2}^{-}\right)$, hydrogenperoxide molecules $\left(\mathrm{H}_{2} \mathrm{O}_{2}\right)$, hydroxyl radicals $\left({ }^{\circ} \mathrm{OH}\right)$, hydrogen dioxide anion $\left(\mathrm{HO}_{2}{ }^{-}\right)$and the hydroperoxy radicals $\left({ }^{\bullet} \mathrm{HO}_{2}\right)[19,43]$

$$
\begin{aligned}
& \mathrm{MO}\left(\mathrm{e}^{-}\right)+\mathrm{O}_{2} \rightarrow \mathrm{MO}+{ }^{\bullet} \mathrm{O}_{2}^{-}, \\
& \mathrm{MO}\left(\mathrm{e}^{-}\right)+{ }^{\bullet} \mathrm{O}_{2}{ }^{-}+2 \mathrm{H}^{+} \rightarrow \mathrm{MO}+\mathrm{H}_{2} \mathrm{O}_{2}, \\
& \mathrm{MO}\left(\mathrm{e}^{-}\right)+\mathrm{H}_{2} \mathrm{O}_{2} \rightarrow \mathrm{MO}+{ }^{\bullet} \mathrm{OH}+\mathrm{OH}^{-}, \\
& { }^{\bullet} \mathrm{O}_{2}{ }^{-}+\mathrm{H}_{2} \mathrm{O}_{2} \rightarrow{ }^{\bullet} \mathrm{OH}+\mathrm{OH}^{-}+\mathrm{O}_{2}, \\
& { }^{\bullet} \mathrm{O}_{2}{ }^{-}+\mathrm{H}^{+} \rightarrow{ }^{\bullet} \mathrm{OH}_{2}, \\
& \mathrm{MO}\left(\mathrm{e}^{-}\right)+{ }^{\bullet} \mathrm{OH}_{2} \rightarrow \mathrm{MO}+\mathrm{HO}_{2}^{-}, \\
& \mathrm{HO}_{2}^{-}+\mathrm{H}^{+} \rightarrow \mathrm{H}_{2} \mathrm{O}_{2}, \\
& 2^{\bullet} \mathrm{OH}_{2} \rightarrow \mathrm{O}_{2}+\mathrm{H}_{2} \mathrm{O}_{2} .
\end{aligned}
$$

While the oxidation reactions initiated by the photogenerated holes are:

$$
\begin{aligned}
& \mathrm{MO}\left(\mathrm{h}^{+}\right)+\mathrm{H}_{2} \mathrm{O} \rightarrow \mathrm{MO}+{ }^{\bullet} \mathrm{OH}+\mathrm{H}^{+}, \\
& \mathrm{MO}\left(\mathrm{h}^{+}\right)+\mathrm{H}_{2} \mathrm{O} \rightarrow \mathrm{MO}+{ }^{\bullet} \mathrm{OH}+\mathrm{H}^{+}, \\
& \mathrm{MO}\left(\mathrm{h}^{+}\right)+\mathrm{OH}^{-} \rightarrow \mathrm{MO}+{ }^{\bullet} \mathrm{OH} .
\end{aligned}
$$

The reactions are terminated as:

$$
\begin{aligned}
& \bullet \mathrm{OH}+\mathrm{H}^{+}+2 \mathrm{e}^{-} \rightarrow \mathrm{H}_{2} \mathrm{O}, \\
& 1 / 2 \mathrm{O}_{2}+2 \mathrm{H}^{+}+2 \mathrm{e}^{-} \rightarrow \mathrm{H}_{2} \mathrm{O} .
\end{aligned}
$$

Metal oxide nanoparticles show photocatalytic activities. Higher the surface area available, more will be the adsorption of the target molecules and higher will be the efficiency of the photocatalytic reactions. $\mathrm{ZnO}$, with a high surface reactivity owing to large number of active sites, has emerged to be an efficient photocatalyst as compared to $\mathrm{TiO}_{2}$. The role of oxygen in the photo destruction of organics on catalyst surfaces has been invesitigated as early as in 1991 [44]. Kinetics models were developed to predict the electron uptake by oxygen. The adsorption of oxygen on illuminated photocatalyst surfaces depends on the number of hydroxyl groups of the surface 45 . It has also been studied that the dependence of degradation rate constants of organics on the dissolved oxygen concentration can be well described by the Langmuir-Hinshelwood ( $\mathrm{L}-\mathrm{H})$ equation [46, 47]. $\mathrm{ZnO}$ is an attractive material for water treatment as it can be tailored to absorb visible light and is capable of ushering in the era of solar photocatalysis. It has an edge over other metal oxides like $\mathrm{TiO}_{2}$ in water purification and other environmental remediation processes as it is soluble in water48 and ends up as metallic zinc in the ecosystem. $\mathrm{TiO}_{2}$ is however insoluble in water and the nanoparticles can persist in the environment ending up as potential environmental contaminants [19] Further, $\mathrm{ZnO}$ can be synthesized under mild conditions and the asymmetry in the crystal structure allows anisotropic growth that can provide large surface to volume ratios [21,33].

Nanoparticles of metal oxides are efficient photocatalysts and can degrade both chemical and biological contaminants. The biggest limitation in the use of nanoparticles for practical applications is the difficulty of removing the particles after the treatment. It is necessary to granulate the photocatalyst nanoparticles into micron-sized particles (hundreds of microns) or load them onto highly porous substrates, which could be used in various flow-through water treatment facilities to avoid the dispersion of these nanoparticles into the environment and its possible consequences on the environment. The removal of these particles requires expensive post purification through nanofiltration usually together with flocculation and there is serious concern that these particles may ultimately affect the ecosystem. The possible harmful effects of nanoparticles on human health and the eco-system are not yet properly understood. This has necessitated the use of photocatalyst supports, which can be regenerated and can be conveniently removed. It is important to understand how engineered nanomaterials migrate, behave, and interact with living organisms and the abiotic components of the environment, and take proactive steps towards the long-term goal of safer design and disposal of products containing these nanoparticles [49]. For example, the problem related to the removal of $\mathrm{ZnO}$ nanoparticles from purified water was addressed by growing $\mathrm{ZnO}$ nanorods on various substrates $[21,50-52]$. Nanowires consists of a large number of low coordination number atoms at the edge and corner sites of the crystal lattice providing numerous catalytically active sites. Considerable scientific interest is seen for the removal of harmful effects of chemical contaminants from groundwater mainly through photocatalysis using nanoparticles of metal oxide like $\mathrm{TiO}_{2}$ and $\mathrm{ZnO}[27,53]$.

Water purification agents should be capable of removing not only chemical, but also microbial contaminants like bacteria, fungi, virus, molds, etc. Photocatalytic inactivation of microorganisms is a complex process and the rate of inactivation varies with the type, concentration and the physiological state of the microbes [54, 55]. The nature, morphology, concentration, and state (slurry or immobilized) of the catalyst material, also, have a great influence on the microbial inactivation rates [24, 56-58]. Among the various bacterial species, Escherichia coli (E. coli) which causes diarrhea have been extensively tested to optimize photocatalytic processes as well as for testing newly designed photo reactors [59]. Apart from E. coli in pure water, the photocatalytic inactivation of other coliform bacteria has also been reported in the literature [60]. $\mathrm{TiO}_{2}$ nanoparticles (Degussa P25) have been used to successfully inactivate different genera of bacteria including Escherichia coli, Pseudomonas aeruginosa, Salmonella typhimurium, and Enterobacter cloacae [61]. Reports of photocatalytic inactivation of model microbes like Escherichia coli, 
Staphylococcus aureus, Saccharomyces cerevisiae, and Aspergilus niger spores have been reported for palladium (Pd) doped $\mathrm{TiO}_{2}$ and tin dioxide $\left(\mathrm{SnO}_{2}\right)$ films grown on glass substrates [62]. The use of $\mathrm{TiO}_{2}$ nanoparticles (Degussa P25) to inactivate bacteria (E. coli, Pseudomonas aeruginosa), fungi (Candida albicans, Fusarium sloani), and protozoa (the trophozoite stage of Acanthamoebe polyphaga), spores (Bacillus subtilis), and cysts under solar light irradiation are also available in the literature [54].

\section{HYDROTHERMAL GROWTH OF NANOSTRUCTURED ZnO PHOTOCATALYST}

Nanostructured $\mathrm{ZnO}$ crystals can be synthesized in solution or gaseous phases [21]. The gas phase synthesis methods are complicated involving expensive processes while the solution phase synthesis are normally done under mild conditions in aqueous solvent. The hydrothermal technique of growing $\mathrm{ZnO}$ nanostructures has received a lot of attention owing to simple growth conditions. For the synthesis of $\mathrm{ZnO}$ nanoparticles, the organometallic process using alcohol as the medium has been widely accepted. This is because of faster nucleation and successive growth in alcoholic solvent as compared to aqueous solvent resulting in well dispersed spherical particles with narrow size distribution $[21,34]$. Even though not commonly used, there are scattered reports in the literature on the aqueous synthesis of $\mathrm{ZnO}$ nanoparticles [63-65].

The growth of $\mathrm{ZnO}$ nanowires on substrates has been an area of intense research for possible applications in areas that require large surface to volume ratios like catalysis, sensing, solar cells, etc. [21, 50, 51, 66] The hydrothermal growth of $\mathrm{ZnO}$ nanowires require sources of zinc ions $\left(\mathrm{Zn}^{2+}\right)$ and hydroxyl ions $\left(\mathrm{OH}^{-}\right)$dissociated in an aqueous solvent [21]. A very commonly used method of growing $\mathrm{ZnO}$ nanowires is the use of an equimolar solution of zinc nitrate hexahydrate and hexamethylenetetramine (HMT) maintained at temperatures in the range of $65^{\circ} \mathrm{C}$ to $95^{\circ} \mathrm{C}[21,66]$. In order to allow the growth of the nanowires to start from the substrate, a thin film of $\mathrm{ZnO}$ nanoparticles is deposited on the substrate through techniques like spin coating, pyrosol, dipping in colloidal solution or dropping and drying. HMT is a non-ionic tetradentate cyclic tertiary amine. HMT, which is highly soluble in water, releases hydroxyl ions through thermal degradation ${ }^{21}$. $\mathrm{OH}^{-}$ions react with $\mathrm{Zn}^{2+}$ ions to form $\mathrm{ZnO}$ [67]; the reactions leading to its formation are summarized below:

$$
\begin{gathered}
\left(\mathrm{CH}_{2}\right)_{6} \mathrm{~N}_{4}+6 \mathrm{H}_{2} \mathrm{O} \rightarrow 6 \mathrm{HCHO}+4 \mathrm{NH}_{3} \\
\mathrm{NH}_{3}+\mathrm{H}_{2} \mathrm{O} \rightarrow \mathrm{NH}_{4}^{+}+\mathrm{OH}^{-} \\
2 \mathrm{OH}^{-}+\mathrm{Zn}^{2+} \rightarrow \mathrm{Zn}(\mathrm{OH})_{2}+\mathrm{H}_{2} \mathrm{O} \\
\mathrm{Zn}(\mathrm{OH})_{2} \rightarrow \mathrm{ZnO}+\mathrm{H}_{2} \mathrm{O}
\end{gathered}
$$

Apart from supplying hydroxyl ions through thermal hydrolysis to drive the precipitation reaction, the role of HMT in the growth of $\mathrm{ZnO}$ nanowires has been widely speculated. It is felt that HMT acts as a kinetic buffer as the rate of its hydrolysis decreases with increasing $\mathrm{pH}$ and vice versa $[50,68]$. In the initial growth stage, the concentration of $\mathrm{Zn}^{2+}$ ions (as also the $\mathrm{pH}$ ) is such that the $\mathrm{ZnO}$ growth will be through the formation of $\mathrm{Zn}(\mathrm{OH})_{2}$. With the steady increase in the $\mathrm{pH}$ resulting from the decrease in the concentration of the $\mathrm{Zn}^{2+}$ ions, $\mathrm{Zn}(\mathrm{OH})_{2}$ becomes thermodynamically unstable and the $\mathrm{Zn}(\mathrm{OH})_{2}$ formed start dissolving. Further growth of the nanowires then happen through direct deposition of $\mathrm{ZnO}$ [69].

\section{MAKING ZnO VISIBLE LIGHT ACTIVE}

In any photocatalytic reactions, apart from factors like type of contaminants and photocatalysts, concentrations, etc., the intensity and wavelength of light irradiation is crucial due to the intrinsic material characteristics [34, 56, 70-72]. $\mathrm{TiO}_{2}$ and $\mathrm{ZnO}$, which are benchmark UV photocatalysts have very low activity in visible light due to their wide band gaps (above $3 \mathrm{eV}$ ) [73, 74]. In order to apply sunlight for photocatalytic degradation of contaminants, the semiconductors need to be modified by incorporation of transition metals [75-94], semiconductor plasmon coupling [72, 95-101], incorporating nonmetals including co-doping of nonmetals [102-106] or by nanostructure engineering (creating oxygen vacancies and oxygen sub-stoichiometry) $[107,108]$. These processes create quasi stable energy states within the band gap facilitating electron hole pair formation at photon energies less than the band gap [33, 34, 109-112]. Visible light photons are then capable of creating excitons leading to photocatalytic reactions. A schematic representation of the energy level and electron transition upon illumination with visible light of doped and undoped $\mathrm{ZnO}$ is shown in Fig. (2).

A very attractive solution to increase visible light absorption (to facilitate solar photocatalysis) is through the incorporation of crystalline defects in metal oxide semiconductors in the form of vacancies and interstitials. Single crystalline $\mathrm{ZnO}$ nanorods has been grown through hydrothermal process $[21,52,113]$. Oxygen vacancies have been introduced in $\mathrm{ZnO}$ nanocrystals and has been reported extensively in the literature [33, 34]. Microwave synthesis have been reported for enhancing crystal defects which render the materials photoactive in the visible region [33, 34]. $\mathrm{ZnO}$ nanoparticles, nanowires and nanorods prepared through rapid crystallization using microwave assisted hydrolysis showed improved efficiency in photocatalytic degradation of organic dyes [33, 34]. Fig. (3) shows the results of the photocatalytic degradation of organic dyes using defect enhanced $\mathrm{ZnO}$ nanoparticles and nanorods [33, 36] represented as plots of $\ln \left(\mathrm{C} / \mathrm{C}_{0}\right)$ versus degradation time, where $\mathrm{C}_{0}$ and $\mathrm{C}$ are the initial and final dye concentrations. The defect engineered $\mathrm{ZnO}$ nanostructures showed higher degradation efficiencies.

Charge transfer mechanisms during photocatalytic reactions were studied using time correlated single photon count spectroscopy [35] to record the electronic transitions resulting from the de-excitation of the electrons to their stable states. Nanoparticles were excited at a wavelength of $375 \mathrm{~nm}$, instead of deep UV light responsible for band edge transitions. An increase in light absorption in samples prepared through a fast crystallization process can be observed as shown in Fig. (3b) inset. The temporal decay of luminescence intensity measured using picosecond spectroscopy with the $\mathrm{ZnO}$ nanoparticle samples revealed an excited state lifetime that is multi-exponential as shown in 


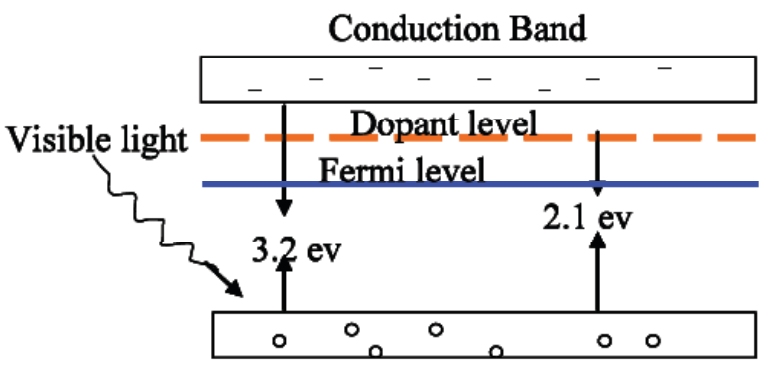

valence Band

a) doped
Conduction Band

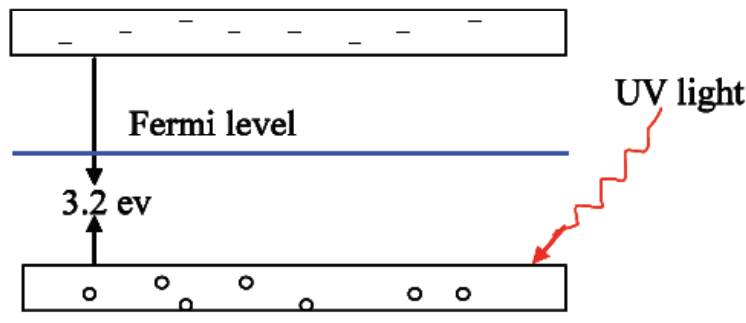

valence Band

b) undoped

Fig. (2). Schematic diagram of the energy level and electron transition upon illumination with visible light of doped and undoped $\mathrm{ZnO}$.
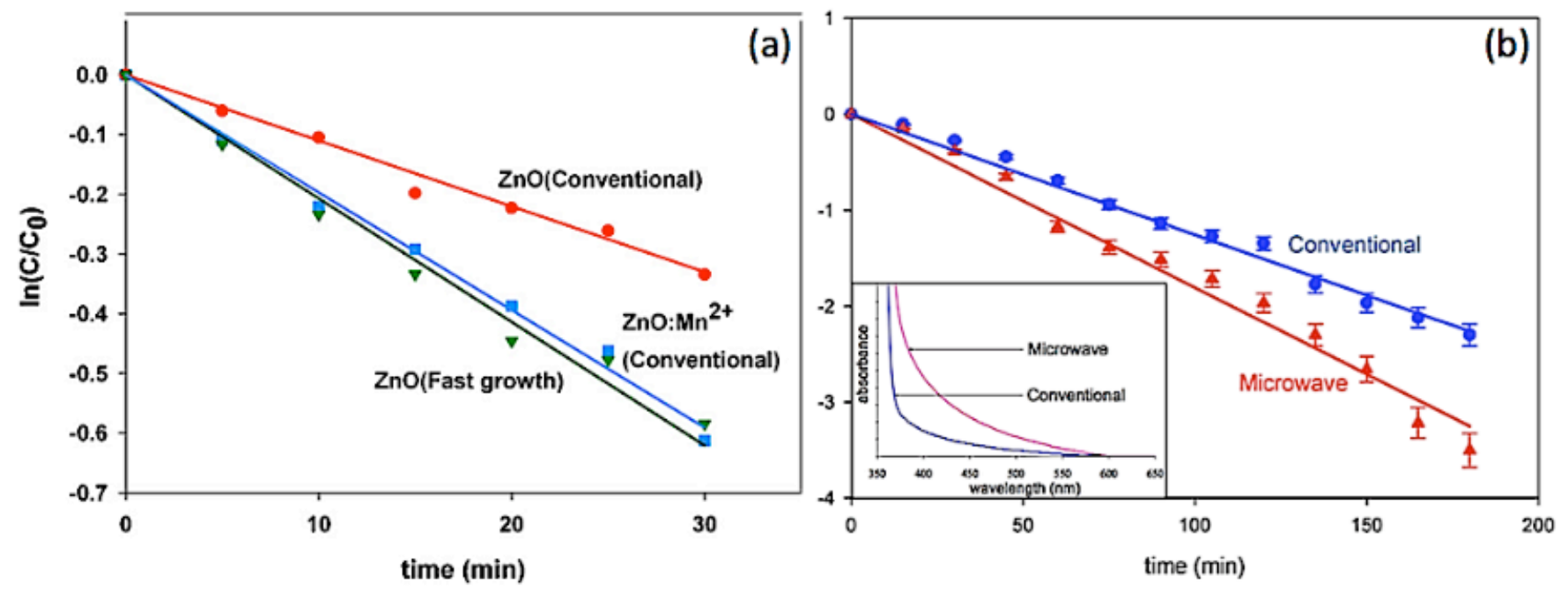

Fig. (3). Photocatalytic decoloration kinetics of a $10 \mu \mathrm{M}$ aqueous solution of methyelene blue with (a) ZnO nanoparticles synthesized through the microwaves assisted fast crystallization technique as well as the pure and Mn-doped $\mathrm{ZnO}$ nanoparticles synthesized through the conventional way of slow crystallization process; the photocatalyst samples were used in the slurry forms, illuminated with 22 klux visible light. The degradation rate constants corresponding to the conventionally hydrolyzed undoped and Mn-doped as well as rapidly grown nanoparticles are $0.0110 \mathrm{~min}^{-1}, 0.0197 \mathrm{~min}^{-1}$, and $0.0207 \mathrm{~min}^{-1}$, respectively (Reproduced with permission from [36]) (b) ZnO nanorods synthesized using conventional and fast crystallization methods (comparable effective surface areas). Inset: UV-vis optical absorption spectra of $\mathrm{ZnO}$ nanorods grown using conventional hydrothermal method and through microwave irradiation of comparable exposed surface area (Reproduced with permission from [33]).

Fig. (4a and $\mathbf{4 b})$. The lifetime values $\left(\tau_{\mathrm{i}}\right)$ of the systems was attributed to the transitions from the excitation band to the valence band and/or the coupled singly or doubly charged defect states. The slower component arises from the electrons transiting from electronic defects or electron deficient states to recombine with holes in the valence band. A much faster initial decay in luminescence in the fastcrystallized particles result from higher surface defects compared to what is observed in conventionally hydrolyzed $\mathrm{ZnO}$ samples.

\section{MULTI-FUNCTIONAL MEMBRANES}

Nanoparticles have found increasing application for water purification but one of its biggest limitations is the difficulty in removing them after the completion of the purification process. This necessitates the use of photocatalyst materials affixed firmly onto supports that can be removed at ease or can be regenerated locally $[16,114-$
116]. Photocatalytic membrane reactors (PMRs) have been demonstrated in which photocatalysis was coupled to a filtration process using membranes 116 . The membrane played both the role of a simple barrier for the photocatalyst and a selective barrier for the molecules to be degraded [117]. In the PMRs, the catalyst are affixed to the membrane (photocatalytic membranes) or suspended in the reaction mixture. Inclusion of semiconducting nanomaterials renders the membranes functionally active instead of simply providing a diffusion barrier for particulate contaminants [15]. Attachment of nanomaterials to membrane supports is crucial to minimize their loss into the purified water as it may have potential impacts on the ecosystem and human health $[17,18]$.

A majority of the reports on photocatalytic membranes available in the literature used nanoparticles of either $\mathrm{TiO}_{2}$ or $\mathrm{ZnO}$ deposited on conventionally used ceramic or polymer membranes [114, 117-132]. However, for nanomaterials 

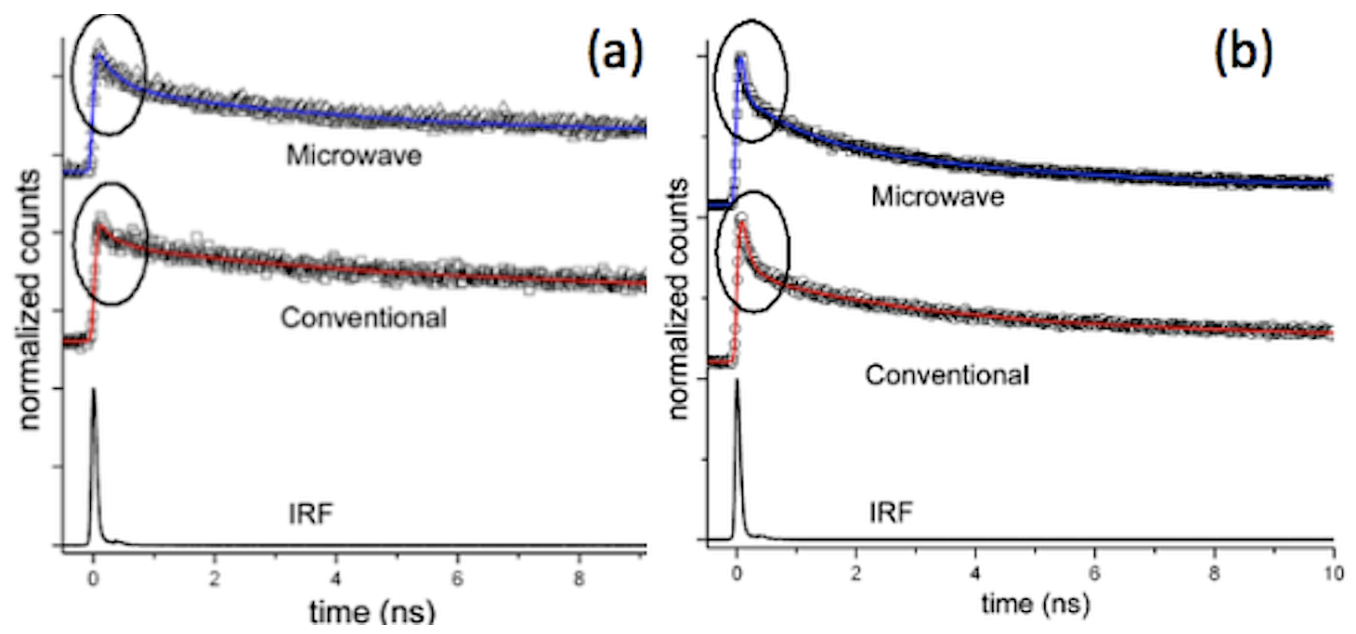

Fig. (4). (a) Fluorescence transients observed at $560 \mathrm{~nm}$ for conventional and $570 \mathrm{~nm}$ for microwave synthesized $\mathrm{ZnO}$ nanoparticles (b) Fluorescence transients observed at $560 \mathrm{~nm}$ for conventional and $570 \mathrm{~nm}$ for microwave synthesized $\mathrm{ZnO}$ nanoparticles in presence of methylene blue (MB) (Reproduced with permission from [35]).

deposited on substrates, one-dimensional nanostructures like nanowires and nanorods offer more effective surface area as compared to nanoparticles [33]. $\mathrm{ZnO}$ nanorods are surface independent and they can be grown on any type of membranes through proper surface treatment $[14,133]$. Our group has successfully grown $\mathrm{ZnO}$ nanorods on a wide variety of membranes made from polymers (polyethylene, polypropylene, etc) [14], glass [38, 50, 51], metals (zinc, aluminium, stainless steel, etc), cellulose based materials like paper [13] and other natural fibers such as cotton [134]. $\mathrm{ZnO}$ nanoparticles are affixed on the membranes following a surface treatment as per the materials with which the membranes are made. These seed nanoparticles are then converted into $\mathrm{ZnO}$ nanowires/nanorods through a c-axis oriented anisotropic crystal growth in a hydrothermal environment $[21,51]$. Very good bonding of the nanoparticles were reported by treating the polymer substrates with thiol followed by immersion in to a colloidal solution of $\mathrm{ZnO}$ nanoparticles over extended periods 14 . Silanes like aminopropyl trimethoxy silane also proved to be good binders for the nanoparticles in case of metal substrates $[135,136]$. Materials with hydroxyl groups like cellulose can easily bind $\mathrm{ZnO}$ nanoparticles through possibly hydrogen bondings and do not require any type of surface treatments $[13,134]$. Fig. (5a) shows scanning electron microscope (SEM) image of $\mathrm{ZnO}$ nanorods grown on polyethylene fibers [14] and the four panels in Fig. (5b) show various micrographs in a clockwise direction of porous structure of the paper hand sheet, $\mathrm{ZnO}$ nanorods growing in the pores, close up view of the $\mathrm{ZnO}$ nanorods and $\mathrm{ZnO}$ nanorods on the top surface of the paper [13].

\section{ANTIMICROBIAL ACTIVITY OF ZnO}

$\mathrm{ZnO}$ nanorods were used to degrade model organic dyes like methylene blue and methyl orange as chemical test contaminants and for the inactivation of Gram negative and Gram positive bacteria (Escherichia coli, Bacillus subtilis and Staphylococcus aureus) as biological test contaminants $[13,33,38]$. It was observed that $\mathrm{ZnO}$ nanorods could effectively degrade dyes like methylene blue and methyl orange (representatives for long chained organic molecules) $[13,33]$. Fig. (6) shows comparative photocatalytic activity of $\mathrm{ZnO}$ nanoparticulate film and $\mathrm{ZnO}$ nanorods of different dimensions [33]. Three nanorod samples of different effective surface areas were used: Sample 1 34.27 $\mathrm{cm}^{2}$, Sample 2 47.54 $\mathrm{cm}^{2}$, Sample 3 39.12 $\mathrm{cm}^{2}$, Nanoparticles $\sim$ $6 \mathrm{~cm}^{2}$. Owing to higher effective surface area of nanorod arrays, higher degradation rates could be observed compared to the nanoparticulate film of the same substrate size.

Inactivation of gram-negative bacteria Escherichia coli and gram-positive bacteria Bacillus subtilis in aqueous matrix by $\mathrm{ZnO}$ nanorods mediated visible light photocatalysis has also been reported [38, 137-140]. The concentration of $\mathrm{Zn}^{2+}$ ions in the aqueous matrix, bacterial cell membrane damage, and DNA degradation were observed after illumination [38]. The inactivation efficiencies for both organisms under illuminated conditions were almost double that under dark conditions. Anomalies in supernatant $\mathrm{Zn}^{2+}$ concentration were observed under both conditions as compared to control treatments, while cell membrane damage and DNA degradation were observed only under illumination. Inactivation in the dark was attributed to the bactericidal effect of $\mathrm{Zn}^{2+}$ ions, while inactivation under illuminated conditions was primarily due to photocatalytic electron injection process. The inactivation of pathogenic bacterial densities by the $\mathrm{ZnO}$ nanorods in the presence of visible light implies potential ex situ application under sunlight for water decontamination at ambient conditions. The levels of dissolved $\mathrm{ZnO}$ post-catalysis were determined to be nonlethal $[141,142]$. The degree of cell membrane damage among the test organisms was measured using a novel technique based on endonuclease pre-treatment, where evidence of possible DNA damage was also found. Representative electrophoregrams of genomic DNA extracted from endonuclease non-treated or treated cells in the dark or under light exposures to $\mathrm{ZnO}$ nanorods are shown in Fig. (7) [38].

$\mathrm{ZnO}$ nanorods grown on paper prepared from cellulose show antibacterial activity and bactericidal effects were reported [13]. Zone of inhibition (absence of viable bacterial cells) upon illumination with visible light is indicative of 

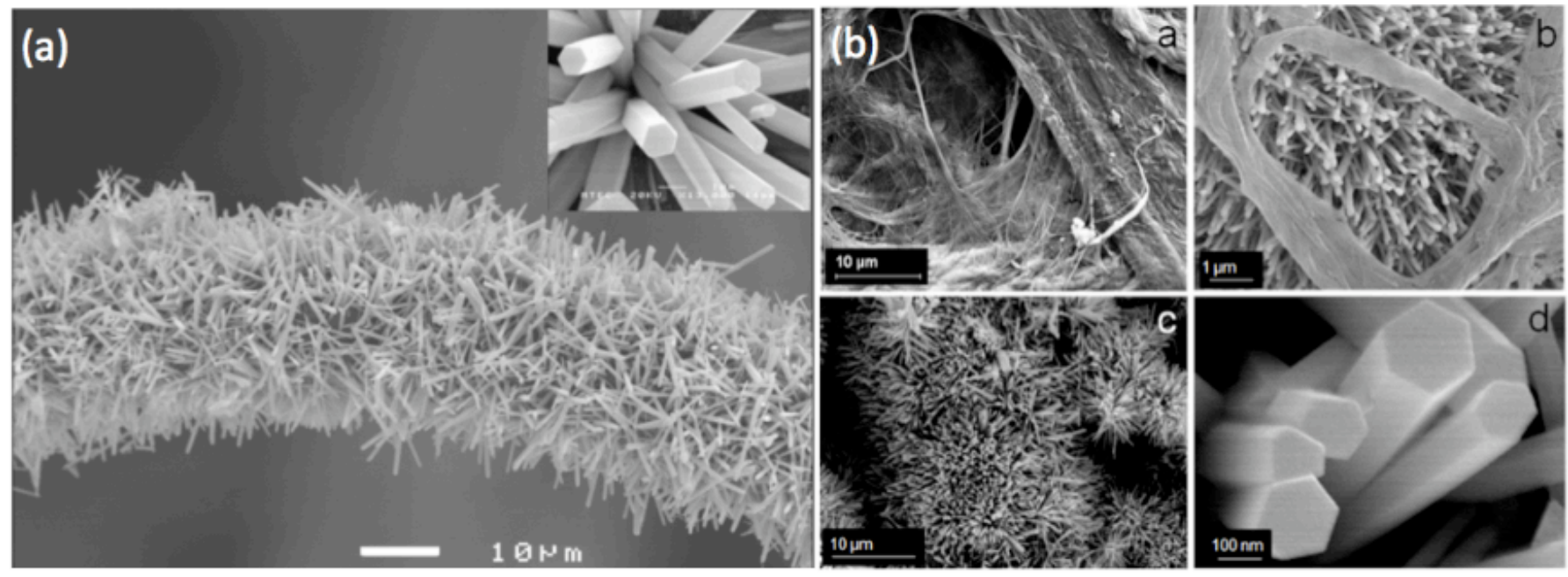

Fig. (5). (a) SEM micrograph of $\mathrm{ZnO}$ nanorods grown on polyethylene fibers. Inset: magnified image of the nanorods (Reproduced with permission from [14]) (b) scanning electron micrographs of $\mathbf{a}$. porous structure of the paper hand sheet $\mathbf{b}$. ZnO nanorods growing in the pores c. $\mathrm{ZnO}$ nanorods on the top surface of the paper d. close up view of the $\mathrm{ZnO}$ nanorods (Reproduced with permission from [13]).

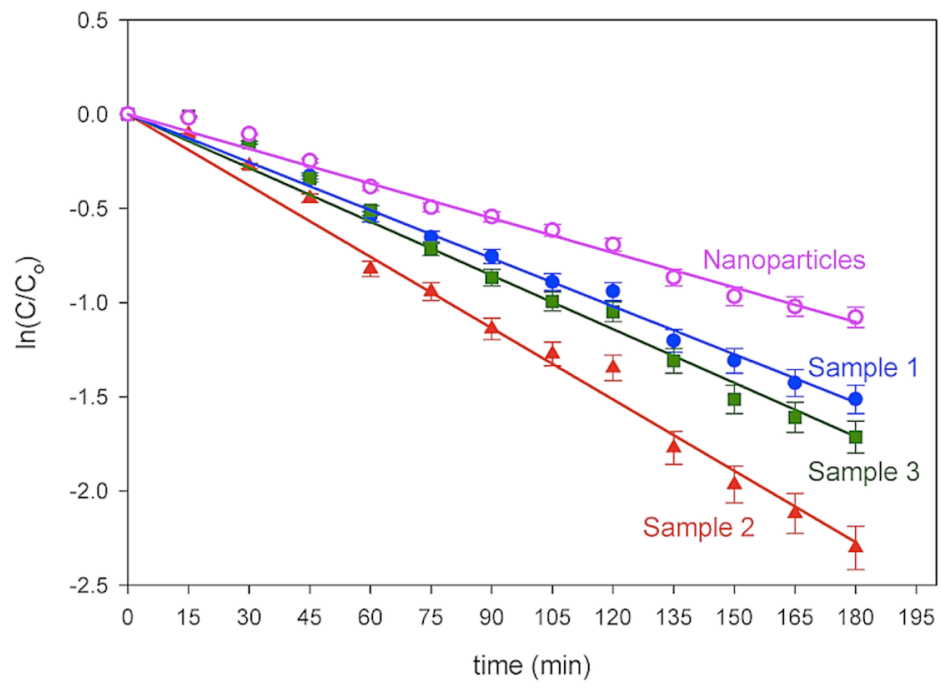

Fig. (6). Photocatalytic degradation of methylene blue using $\mathrm{ZnO}$ nanoparticles and nanorods on glass substrates upon excitation with light from a tungsten halogen lamp ( 72 klux) (Reproduced with permission from [33]).

(a)

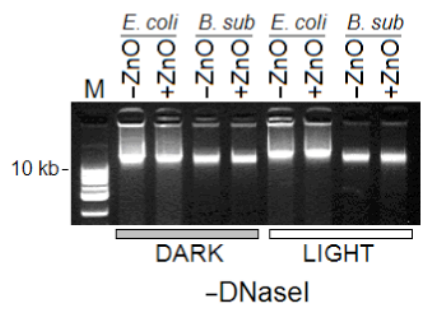

(b)

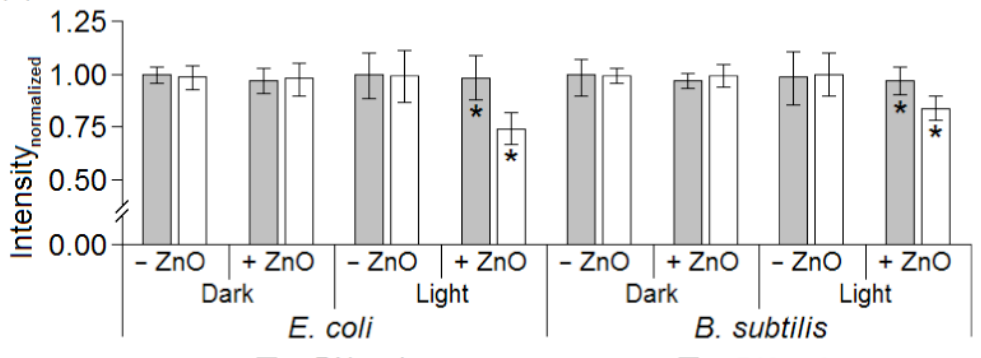


Fig. (7). contd...

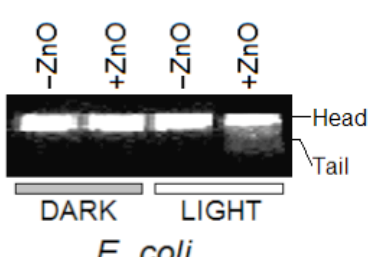

E. coli

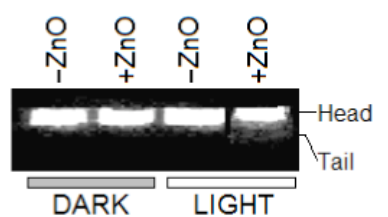

B. subtilis

Fig. (7). Visualization of genomic DNA damage in model organisms induced by $\mathrm{ZnO}$ mediated visible light photocatalysis. (a) Representative electrophoregrams of genomic DNA extracted from endonuclease non-treated or treated cells following dark or light exposures to $\mathrm{ZnO}$ nanorods. (b) Average signals (A260) from double-stranded DNA, normalized between endonuclease non-treated and treated pairs. (c) Representative electrophoregrams of genomic DNA after the modified comet assay (Reproduced with permission from [38]).

photocatalytic immobilization. It was observed that the bacteria get immobilized on the surface of the photocatalytic paper and also could not flourish in the vicinity of the $\mathrm{ZnO}$ treated paper. Fig. (8) shows the results of the antibacterial experiments. Photocatalytic paper can be an attractive functional membrane for application in water purification.

\section{PHOTOCATALYSIS IN ACTION}

\section{Water Purifier}

Inactivation of waterborne bacteria like Escherichia coli (E. coli), Bacillus subtilis (B. subtilis) and Staphylococcus aureus ( $S$. aureus) by $\mathrm{ZnO}$ nanorods mediated visible light photocatalysis has been studied [38]. The inactivation efficiencies for both organisms under illuminated conditions were almost double that under dark conditions. Anomalies in supernatant $\mathrm{Zn}^{2+}$ concentration were observed under both conditions as compared to control treatments, while cell membrane damage and DNA degradation were observed only under illumination. Inactivation in the dark was attributed to the bactericidal effect of $\mathrm{Zn}^{2+}$ ions, while under illuminated conditions the inactivation is alleviated due to photocatalytic electron injection process. The $\mathrm{Zn}^{2+}$ ions released through dissolution binds to the tip of pili of bacteria and prolong the lag phase of the bacterial growth cycle thereby checking reproduction. Strong radicals generated through photocatalysis can disrupt bacterial cell walls creating permanent damage.

The inactivation of pathogenic bacterial densities by the $\mathrm{ZnO}$ nanorods in the presence of visible light implies potential ex situ application under sunlight for water decontamination at ambient conditions. The levels of dissolved $\mathrm{ZnO}$ post-catalysis were determined to be nonlethal. The degree of cell membrane damage among the test organisms was measured using a novel technique based on endonuclease pre-treatment, where evidence of possible DNA damage was also found [38].

An antibacterial water purifier developed using $\mathrm{ZnO}$ nanorods grown on polyethylene fibers is shown in Fig. (9a). The water purifier was tested on two model bacteria $E$. coli and $S$. aureus. Up to $99 \%$ of $E$. coli and $S$. aureus in spiked
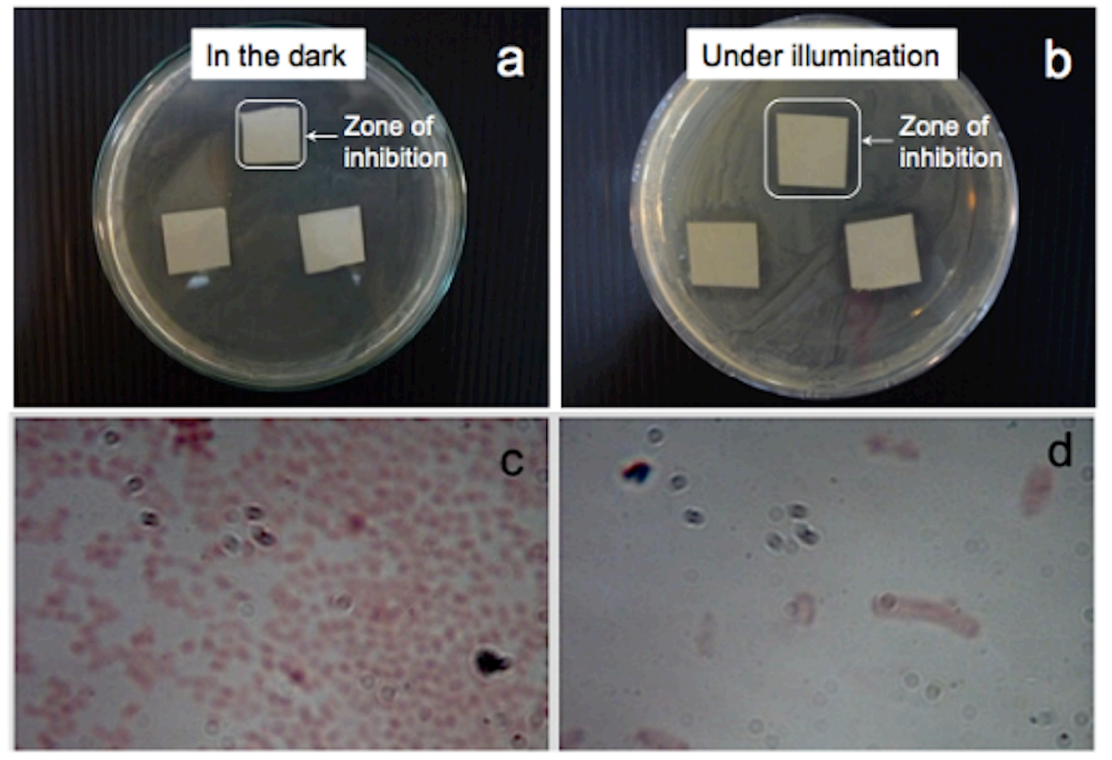

Fig. (8). Results of antibacterial experiments carried out using photocatalytic paper (Sample 1) after incubation for $48 \mathrm{~h}$ (a) in the dark and (b) under illumination with a tungsten halogen lamp. The inhibition zone increased from $1.7 \times 1.7 \mathrm{~cm}^{2}$ in the dark to $2.1 \times 2.1 \mathrm{~cm}{ }^{2}$ under visible-light illumination. Optical images taken at a magnification of $1000 \mathrm{X}$ (c) outside the inhibition zone and (d) inside the inhibition zone (Reproduced with permission from [13]). 


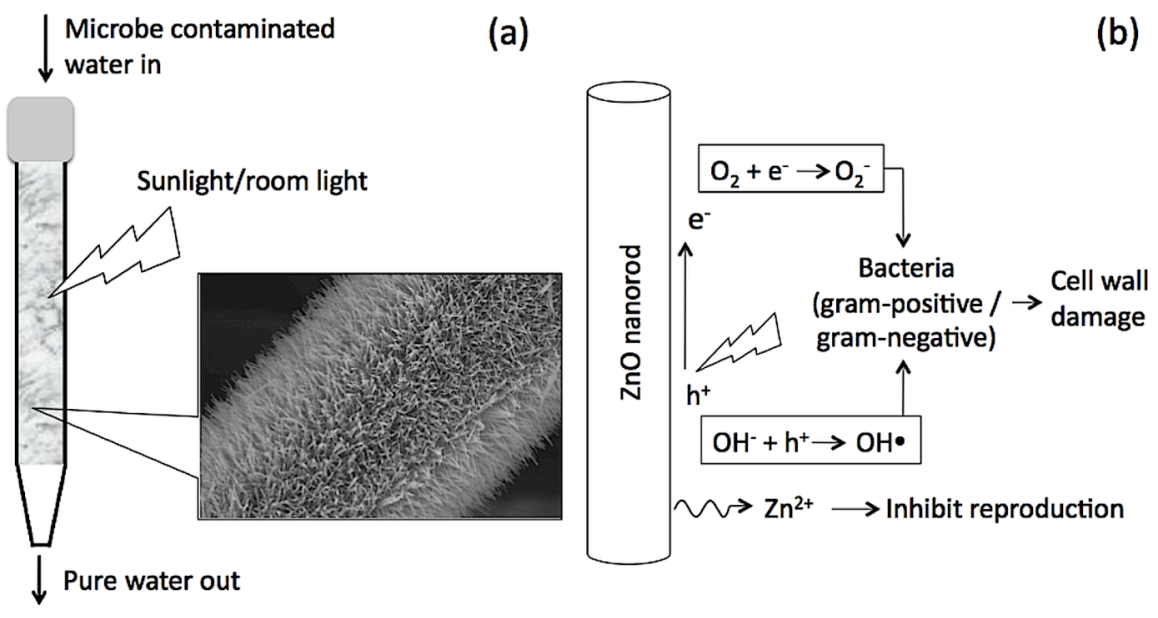

Fig. (9). Schematic representations of (a) water purifier comprising of $\mathrm{ZnO}$ nanorods on polyethylene fibers enclosed in a glass tube (b) mechanism of bacterial immobilization by $\mathrm{ZnO}$ nanorods. Free electrons interact with oxygen forming superoxides while the holes convert hydroxyl ions into highly reactive hydroxyl radicals [143] (Reproduced by permission of The Royal Society of Chemistry (RSC) on behalf of the Centre National de la Recherche Scientifique (CNRS) and the RSC).

water containing about $10^{10}$ colony forming units (CFU) of bacterial cells could be immobilized under sunlight, while under room lighting conditions, $80 \%$ of $E$. coli and $59 \%$ of $S$. aureus cells could be inactivated. This type of water purifiers can be effectively utilized in disaster areas where there is acute scarcity of drinking water and an availability of sunshine. Two mechanisms come play roles in the antibacterial activity of the $\mathrm{ZnO}$ nanorods: slow release of zinc ions through dissolution of $\mathrm{ZnO}$ and the formation of reactive oxygen species (ROS) through photocatalysis. The mechanism of bacterial inactivation with $\mathrm{ZnO}$ nanowires is shown schematically in Fig. (9b).

\section{CONCLUSIONS}

Technological advancement has severely affected the environment leading to a disparity in the biosphere. Innovative applications of nanotechnology using engineered catalysts exploiting unique properties of nanomaterials are capable of making an impact include the minimization of industrial wastes, sensors to detect toxic molecules in the biosphere. Improved nanostructured photocatalysts are useful for degrading toxic contaminants into benign fragments utilizing solar energy. The concentration of toxic materials and infectious microorganism in the natural resources of drinking water is constantly increasing causing severe environmental pollution. Availability of safe drinking water to people in developing countries has become a serious challenge. Heterogeneous photocatalysis is a promising technique to control environmental pollution whereby toxic organic compounds can be effectively degraded into harmless fragments through a process called photocatalysis using semiconducting nanostructures. Visible light photocatalysis to utilize solar energy, as visible radiation constitutes a major share ( $\sim 46 \%)$ of the solar spectrum compared to UV light ( 7\%), is getting increasingly popular. Photocatalysis using visible light has been reported to be possible through doping of semiconductors with transition metals to reduce the effective band gap and seem to be attractive for water treatments. This technology is in its infancy and has a potential of being applied across the water treatment processes.

\section{CONFLICT OF INTEREST}

The author(s) confirm that this article content has no conflict of interest.

\section{ACKNOWLEDGEMENTS}

The authors would like to acknowledge colleagues from the Centre of Excellence in Nanotechnology, Asian Institute of Technology, Thailand for their comments and suggestions.

\section{REFERENCE}

[1] http://www.eoearth.org/article/Human_population_explosion (accessed September 3, 2012)

[2] Baruah, S.; Dutta, J. Nanotechnology applications in pollution sensing and degradation in agriculture: a review. Environ. Chem. Lett., 2009, 7(3), 1-14.

[3] Sugunan, A.; Dutta, J. Pollution Treatment, Remediation, and Sensing. In Nanotechnology, Harald, K., Ed. Wiley-VCH: Weinheim, 2008; Vol. 3

[4] (USGS), U. G. S., The Water Cycle: Fresh Water Storage. . 2010.

[5] DOE), U. D. E. U., Energy Demands on Water Resources: Report to Congress on the Interdependency of Energy and Water. US DOE, Washington, DC. 2006.

[6] (UN), U. N., International Decade for Action Water for Life, 20052015: Water Scarcity. 2010 (accessed August 18, 2012) .

[7] http://www.who.int/infectious-diseasereport/pages/textonly.html.(accessed July 26, 2012)

[8] Baruah, S.; Kitsomboonloha, R.; Myint, M. T. Z.; Dutta, J., Nanoparticle Applications for Environmental Control and Remediation. In Nanoparticles: Synthesis, Characterization and Applications, Chaughule, R. S.; Ramanujan, R. V., Eds. American Scientific Publishers, Valencia, California, USA: 2009; pp 195-216.

[9] Gopal, K.; Tripathy, S. S.; Bersillon, J. L.; Dubey, S. P. Chlorination byproducts, their toxicodynamics and removal from drinking water. J. Hazard. Mater. 2007, 140 (1-2), 1-6.

[10] Sadiq, R.; Rodriguez, M. J. Disinfection by-products (DBPs) in drinking water and predictive models for their occurrence: A review. Sci. Total Environ. 2004, 321 (1-3), 21-46. 
[11] Roco, M. C., Handbook on Nanoscience, Engineering and Technology 2nd ed.; Taylor \& Francis 2007.

[12] Hornyak, G. L.; Dutta, J.; Tibbals, H. F.; Rao, A. K., Introduction to nanoscience. CRC Press: 2008.

[13] Baruah, S.; Jaisai, M.; Imani, R.; Nazhad, M. M.; Dutta, J., Photocatalytic paper using zinc oxide nanorods. Sci. Technol. Adv. Mater. 2010, 11 (5), 055002.

[14] Baruah, S.; Thanachayanont, C.; Dutta, J., Growth of $\mathrm{ZnO}$ nanowires on nonwoven polyethylene fibers. Sci. Technol. Adv. Mater. 2008, 9 (2), 025009.

[15] Li, Q.; Mahendra, S.; Lyon, D. Y.; Brunet, L.; Liga, M. V.; Li, D.; Alvarez, P. J. J., Antimicrobial nanomaterials for water disinfection and microbial control: Potential applications and implications. Water Res. 2008, 42 (18), 4591-4602.

[16] Marcucci, M.; Ciabatti, I.; Matteucci, A.; Vernaglione, G., Membrane technologies applied to textile wastewater treatment. In Annals of the New York Academy of Sciences, 2003; Vol. 984, pp 53-64.

[17] Hirano, S., A current overview of health effect research on nanoparticles. Environmental Health and Preventive Medicine 2009, 14, 223-225.

[18] Wiesner, M. R.; Lowry, G. V.; Alvarez, P.; Dionysiou, D.; Biswas, P., Assessing the risks of manufactured nanomaterials. Environ. Sci. Technol. 2006, 40 (14), 4336-4345.

[19] Baruah, S.; Dutta, J., Nanotechnology applications in pollution sensing and degradation in agriculture. Environ. Chem. Lett. 2009, 7, 191-204.

[20] Baruah, S.; Dutta, J., Zinc stannate nanostructures: Hydrothermal synthesis. Sci. Technol. Adv. Mater. 2011, 12 (1), 013004.

[21] Baruah, S.; Dutta, J., Hydrothermal growth of $\mathrm{ZnO}$ nanostructures. Science and Technology of Advanced Materials 2009, 10, 013001.

[22] Jongnavakit, P.; Amornpitoksuk, P.; Suwanboon, S.; Ratana, T., Surface and photocatalytic properties of $\mathrm{ZnO}$ thin film prepared by sol-gel method. Thin Solid Films 2012, 520, 5561-5567.

[23] Kim, J.; Yong, K., A facile, coverage controlled deposition of Au nanoparticles on $\mathrm{ZnO}$ nanorods by sonochemical reaction for enhancement of photocatalytic activity. J. Nanopart. Res. 2012, 14, $1-10$.

[24] Adams, L. K.; Lyon, D. Y.; Alvarez, P. J. J. Comparative ecotoxicity of nanoscale $\mathrm{TiO}_{2}, \mathrm{SiO}_{2}$, and $\mathrm{ZnO}$ water suspensions. Water Res. 2006, 40 (19), 3527-3532.

[25] Aguedach, A.; Brosillon, S.; Morvan, J.; Lhadi, E. K. Photocatalytic degradation of azo-dyes reactive black 5 and reactive yellow 145 in water over a newly deposited titanium dioxide. Appl. Catal., B 2005, 57 (1), 55-62.

[26] Benabbou, A. K.; Derriche, Z.; Felix, C.; Lejeune, P.; Guillard, C., Photocatalytic inactivation of Escherischia coli. Effect of concentration of $\mathrm{TiO} 2$ and microorganism, nature, and intensity of UV irradiation. Appl. Catal., B 2007, 76 (3-4), 257-263.

[27] Bianco-Prevot, A.; Fabbri, D.; Pramauro, E.; Morales-Rubio, A.; De la Guardia, M. Continuous monitoring of photocatalytic treatments by flow injection. Degradation of dicamba in aqueous $\mathrm{TiO}_{2}$ dispersions. Chemosphere 2001, 44 (2), 249-255.

[28] Chatterjee, D.; Dasgupta, S. Visible light induced photocatalytic degradation of organic pollutants. J. Photochem. Photobiol., C: 2005, 6 (2-3), 186-205.

[29] Chen, J. Q.; Wang, D.; Zhu, M. X.; Gao, C. J. Study on degradation of methyl orange using pelagite as photocatalyst. J. Hazard. Mater. 2006, 138 (1), 182-186.

[30] Cho, M.; Chung, H.; Choi, W.; Yoon, J. Linear correlation between inactivation of $\mathrm{E}$. coli and $\mathrm{OH}$ radical concentration in $\mathrm{TiO}_{2}$ photocatalytic disinfection. Water Res. 2004, 38 (4), 1069-1077.

[31] Evgenidou, E.; Fytianos, K.; Poulios, I. Semiconductor-sensitized photodegradation of dichlorvos in water using $\mathrm{TiO}_{2}$ and $\mathrm{ZnO}$ as catalysts. Applied Catalysis B: Environmental 2005, 59 (1-2), 8189.

[32] Fujishima, A.; Rao, T. N.; Tryk, D. A. Titanium dioxide photocatalysis. J. Photochem. Photobiol., C: 2000, 1 (1), 1-21.

[33] Baruah, S.; Mahmood, M. A.; Myint, M. T. Z.; Bora, T.; Dutta, J. Enhanced visible light photocatalysis through fast crystallization of zinc oxide nanorods. Beilstein J. Nanotechnol. 2010, 1, 14-20.
[34] Baruah, S.; Rafique, R. F.; Dutta, J. Visible light photocatalysis by tailoring crystal defects in zinc oxide nanostructures. Nano 2008, 3 (5), 399-407.

[35] Baruah, S.; Sinha, S. S.; Ghosh, B.; Pal, S. K.; Raychaudhuri, A $\mathrm{K}$.; Dutta, J. Photo-reactivity of $\mathrm{ZnO}$ nanoparticles in visible light: Effect of surface states on electron transfer reaction. J. Appl. Phys. 2009, 105, 074308 .

[36] Mahmood, M. A.; Baruah, S.; Dutta, J. Enhanced visible light photocatalysis by manganese doping or rapid crystallization with ZnO nanoparticles. Mater. Chem. Phys. 2011, 30 (1-2), 531-535.

[37] Makhal, A.; Sarkar, S.; Bora, T.; Baruah, S.; Dutta, J.; Raychaudhuri, A. K.; Pal, S. K. Role of resonance energy transfer in light harvesting of zinc oxide-based dye-sensitized solar cells. $J$. Phys. Chem. C 2010, 114 (23), 10390-10395.

[38] Sapkota, A.; Anceno, A. J.; Baruah, S.; Shipin, O. V.; Dutta, J. Zinc oxide nanorod mediated visible light photoinactivation of model microbes in water. Nanotechnology 2011, 22 (21), 215703.

[39] Chang, M.; Chen, A.; He, H.; Ma, L.; Li, C., Ni anode modified by layer by layer assembly and its application in water electrolysis assisted by photocatalysis. Huagong Xuebao/CIESC Journal 2012, 63, 2195-2201.

[40] Fenoll, J.; Flores, P.; Hellin, P.; Martinez, C. M.; Navarro, S., Photodegradation of eight miscellaneous pesticides in drinking water after treatment with semiconductor materials under sunlight at pilot plant scale. Chem. Eng. J. 2012, 204-205, 54-64.

[41] Lam, S. M.; Sin, J. C.; Abdullah, A. Z.; Mohamed, A. R., Degradation of wastewaters containing organic dyes photocatalysed by zinc oxide: A review. Desalin. Water Treat. 2012, 41, 131-169.

[42] Gaya, U. I.; Abdullah, A. H. Heterogeneous photocatalytic degradation of organic contaminants over titanium dioxide: A review of fundamentals, progress and problems. J. Photochem. Photobiol., C 2008, 9 (1), 1-12.

[43] Banerjee, S.; Gopal, J.; Muraleedharan, P.; Tyagi, A. K.; Raj, B. Physics and chemistry of photocatalytic titanium dioxide: Visualization of bactericidal activity using atomic force microscopy. Current Science 2006, 90 (10), 1378-1383.

[44] Gerischer, H.; Heller, J. The role of oxygen in photooxidation of organic molecules on semiconductor particles. J. Phys. Chem. 1991, 95, 5261-5267.

[45] Bickley, R. I.; Stone, F. S. Photoadsorption and photocatalysis at rutile surfaces: I. Photoadsorption of oxygen. J. Catal. 1973, 31, 389-397.

[46] Chen, D.; Sivakumar, M.; Ray, A. K. Heterogeneous Photocatalysis in Environmental Remediation. Chem. Eng. Mineral Process 2000, $8,505-550$.

[47] Matos, J.; Laine, J.; Hermann, J. M. Effect of the Type of Activated Carbons on the Photocatalytic Degradation of Aqueous Organic Pollutants by UV-Irradiated Titania. Appl. Catal., B 1998, 18, 281-291.

[48] Han, J.; Qiu, W.; Gao, W., Potential dissolution and photodissolution of $\mathrm{ZnO}$ thin films. J. Hazard. Mater. 2010, 178, 115122.

[49] Alvarez, P. J. J.; Colvin, V.; Lead, J.; Stone, V. A. N. Research priorities to advance eco-responsible nanotechnology. ACS Nano 2009, 3, 1616-1619.

[50] Baruah, S.; Dutta, J., pH-dependent growth of zinc oxide nanorods. J. Cryst. Growth 2009, 311 (8), 2549-2554.

[51] Baruah, S.; Dutta, J. Effect of seeded substrates on hydrothermally grown ZnO nanorods. J. Sol-Gel Sci. Technol. 2009, 50 (3), 456464.

[52] Sugunan, A.; Warad, H. C.; Boman, M.; Dutta, J. Zinc oxide nanowires in chemical bath on seeded substrates: Role of hexamine. J. Sol-Gel Sci. Technol. 2006, 39 (1 SPEC. ISS.), 49-56.

[53] Herrmann, J. M.; Guillard, C. Photocatalytic degradation of pesticides in agricultural used waters. Comptes Rendus de l'Academie des Sciences - Series IIc: Chemistry 2000, 3 (6), 417-422.

[54] Lonnen, J.; Kilvington, S.; Kehoe, S. C.; Al-Touati, F.; McGuigan, K. G. Solar and photocatalytic disinfection of protozoan, fungal and bacterial microbes in drinking water. Water Research 2005, 39 (5), 877-883.

[55] Rincon, A. G.; Pulgarin, C. Bactericidal action of illuminated $\mathrm{TiO}_{2}$ on pure Escherichia coli and natural bacterial consortia: Post- 
irradiation events in the dark and assessment of the effective disinfection time. Appl. Catal., B 2004, 49 (2), 99-112.

[56] Huang, N.; Xiao, Z.; Huang, D.; Yuan, C. Photochemical disinfection of Escherichia coli with $\mathrm{a} \mathrm{TiO}_{2}$ colloid solution and a self-assembled $\mathrm{TiO}_{2}$ thin film. Supramolecular Science 1998, 5 (5-6), 559-564.

[57] Qi, L.; Xu, Z.; Jiang, X.; Hu, C.; Zou, X. Preparation and antibacterial activity of chitosan nanoparticles. Carbohydrate Research 2004, 339 (16), 2693-2700.

[58] Sondi, I.; Salopek-Sondi, B. Silver nanoparticles as antimicrobial agent: A case study on E. coli as a model for Gram-negative bacteria. J. Colloid Interface Sci. 2004, 275 (1), 177-182.

[59] Krishna, V.; Yanes, D.; Imaram, W.; Angerhofer, A.; Koopman, B.; Moudgil, B. Mechanism of enhanced photocatalysis with polyhydroxy fullerenes. Appl. Catal. B 2008, 79 (4), 376-381.

[60] Gelover, S.; Gomez, L. A.; Reyes, K.; Teresa Leal, M. A practical demonstration of water disinfection using $\mathrm{TiO}_{2}$ films and sunlight. Water Research 2006, 40 (17), 3274-3280.

[61] Ibanez, J. A.; Litter, M. I.; Pizarro, R. A. Photocatalytic bactericidal effect of $\mathrm{TiO}_{2}$ on Enterobacter cloacae. Comparative study with other Gram (-) bacteria. J. Photochem. Photobiol. A 2003, 157 (1), 81-85.

[62] Erkan, A.; Bakir, U.; Karakas, G., Photocatalytic microbial inactivation over Pd doped $\mathrm{SnO}_{2}$ and $\mathrm{TiO}_{2}$ thin films. J. Photochem. Photobiol. A 2006, 184 (3), 313-321.

[63] Baruwati, B.; Kumar, D. K.; Manorama, S. V. Hydrothermal synthesis of highly crystalline $\mathrm{ZnO}$ nanoparticles: A competitive sensor for LPG and EtOH. Sens. Actuators, B 2006, 119 (2), 676682.

[64] Lu, C. H.; Yeh, C. H. Influence of hydrothermal conditions on the morphology and particle size of zinc oxide powder. Ceram. Int. 2000, 26 (4), 351-357.

[65] Chen, D.; Jiao, X.; Cheng, G. Hydrothermal synthesis of zinc oxide powders with different morphologies. Solid State Commun. 2000, 113 (6), 363-366.

[66] Vayssieres, L. Growth of arrayed nanorods and nanowires of $\mathrm{ZnO}$ from aqueous solutions. Adv. Mater. 2003, 15 (5), 464-466.

[67] http://web.worldbank.org/WBSITE/EXTERNAL/COUNTRIES/ SOUTHASIAEXT/ (accessed July 23, 2012)

[68] Govender, K.; Boyle, D. S.; Kenway, P. B.; O'Brien, P. Understanding the factors that govern the deposition and morphology of thin films of $\mathrm{ZnO}$ from aqueous solution. J. Mater. Chem. 2004, 14 (16), 2575-2591.

[69] Ashfold, M. N. R.; Doherty, R. P.; Ndifor-Angwafor, N. G.; Riley, D. J.; Sun, Y. The kinetics of the hydrothermal growth of ZnO nanostructures. Thin Solid Films 2007, 515 (24 SPEC. ISS.), 8679-8683.

[70] Hayakawa, T.; Kuroiwa, A.; Higashi, E.; Nakano, K. Photoinduced Bactericidal Effect of Titania Thin Film against Legionella pneumophila. Medical bulletin of Fukuoka University 2007, 34 (2), 71-81.

[71] Leung, T. Y.; Chan, C. Y.; Hu, C.; Yu, J. C.; Wong, P. K. Photocatalytic disinfection of marine bacteria using fluorescent light. Water Research 2008, 42 (19), 4827-4837.

[72] Rehman, S.; Ullah, R.; Butt, A. M.; Gohar, N. D. Strategies of making $\mathrm{TiO}_{2}$ and $\mathrm{ZnO}$ visible light active. J. Hazard. Mater. 2009, $170(2-3), 560-569$.

[73] Miyauchi, M.; Nakajima, A.; Watanabe, T.; Hashimoto, K. Photocatalysis and photoinduced hydrophilicity of various metal oxide thin films. Chem. Mater. 2002, 14 (6), 2812-2816.

[74] Srikant, V.; Clarke, D. R. On the optical band gap of zinc oxide. $J$. Appl. Phys. 1998, 83 (10), 5447-5451.

[75] Duan, L.; Zhao, X.; Liu, J.; Geng, W.; Xie, H.; Chen, S. Structural, thermal and magnetic investigations of heavily Mn-doped ZnO nanoparticles. J. Magn. Magn. Mater. 2011, 323 (18-19), 2374-2379.

[76] Kumarakuru, H.; Cherns, D.; Fuge, G. M. The growth of Al-doped $\mathrm{ZnO}$ nanorods on c-axis sapphire by pulsed laser deposition. Surf. Coat. Technol. 2011, 205 (21-22), 5083-5087.

[77] Li, P.; Deng, S. H.; Li, Y. B.; Huang, J.; Liu, G. H.; Zhang, L. Aluminum and nitrogen impurities in Wurtzite $\mathrm{ZnO}$ : Firstprinciples studies. Physica B 2011, 406 (17), 3125-3129.
[78] Li, Z. Z.; Chen, Z. Z.; Huang, W.; Chang, S. H.; Ma, X. M. The transparence comparison of $\mathrm{Ga}$ - and $\mathrm{Al}$-doped $\mathrm{ZnO}$ thin films. Appl. Surf. Sci. 2011, 257 (20), 8486-8489.

[79] Maldonado, A.; Rodríguez-Baez, J.; De La L. Olvera, M. Physical properties of indium and fluorine codoped zinc oxide thin films deposited by chemical spray. Mater. Chem. Phys. 2011, 129 (1-2), 109-115.

[80] Roy, T. K.; Ghosh, A.; Bhowmick, D.; Sanyal, D.; Koley, S.; Chakrabarti, A. Effect of silica doping on the densification and grain growth in zinc oxide. Ceram. Int. 2011, 37 (7), 2679-2687.

[81] Shtereva, K.; Flickyngerova, S.; Tvarozek, V.; Novotny, I.; Kovac, J.; Vincze, A. Characterization of gallium-nitrogen co-doped zinc oxide thin films prepared by RF diode sputtering. Vacuum 2012 , 86(6), 652-656.

[82] Vimalkumar, T. V.; Poornima, N.; Jinesh, K. B.; Kartha, C. S.; Vijayakumar, K. P. On single doping and co-doping of spray pyrolysed $\mathrm{ZnO}$ films: Structural, electrical and optical characterisation. Appl. Surf. Sci. 2011, 257 (20), 8334-8340.

[83] Yun, S.; Lim, S. Effect of Al-doping on the structure and optical properties of electrospun zinc oxide nanofiber films. J. Colloid Interface Sci. 2011, 360 (2), 430-439.

[84] Zhao, M.; Wang, X.; Ning, L.; Jia, J.; Li, X.; Cao, L. Electrospun $\mathrm{Cu}$-doped $\mathrm{ZnO}$ nanofibers for $\mathrm{H}_{2} \mathrm{~S}$ sensing. Sens. Actuators, $B$ 2011, 156 (2), 588-592.

[85] Guo, M. L.; Zhang, X. D.; Liang, C. T. Concentration-dependent electronic structure and optical absorption properties of B-doped anatase $\mathrm{TiO}_{2}$. Physica B 2011, 406 (17), 3354-3358.

[86] Li, Y.; Ma, M.; Chen, W.; Li, L.; Zen, M. Preparation of Ag-doped TiO2 nanoparticles by a miniemulsion method and their photoactivity in visible light illuminations. Mater. Chem. Phys. 2011, 129 (1-2), 501-505.

[87] Liu, Y.; Yang, Q.; Wei, J. H.; Xiong, R.; Pan, C. X.; Shi, J. Synthesis and photocatalytic activity of hydroxyapatite modified nitrogen-doped $\mathrm{TiO}_{2}$. Mater. Chem. Phys. 2011, 129 (1-2), 654659.

[88] Mechiakh, R.; Ben Sedrine, N.; Chtourou, R. Sol-gel synthesis, characterization and optical properties of mercury-doped $\mathrm{TiO}_{2}$ thin films deposited on ITO glass substrates. Appl. Surf. Sci. 2011, 257 (21), 9103-9109.

[89] Putta, T.; Lu, M. C.; Anotai, J. Photocatalytic activity of tungstendoped $\mathrm{TiO} 2$ with hydrothermal treatment under blue light irradiation. J. Environ. Manage. 2011, 92 (9), 2272-2276.

[90] Rauf, M. A.; Meetani, M. A.; Hisaindee, S. An overview on the photocatalytic degradation of azo dyes in the presence of $\mathrm{TiO}_{2}$ doped with selective transition metals. Desalination 2011, 276 (13), 13-27.

[91] Sahu, M.; Suttiponparnit, K.; Suvachittanont, S.; Charinpanitkul, T.; Biswas, P. Characterization of doped $\mathrm{TiO}_{2}$ nanoparticle dispersions. Chem. Eng. Sci. 2011, 66 (15), 3482-3490.

[92] Yan, G.; Zhang, M.; Hou, J.; Yang, J. Photoelectrochemical and photocatalytic properties of $\mathrm{N}+\mathrm{S}$ co-doped $\mathrm{TiO}_{2}$ nanotube array films under visible light irradiation. Mater. Chem. Phys. 2011, 129 (1-2), 553-557.

[93] Yang, J.; Dai, J.; Li, J. Synthesis, characterization and degradation of Bisphenol A using Pr, N co-doped $\mathrm{TiO}_{2}$ with highly visible light activity. Appl. Surf. Sci. 257 (21), 8965-8973.

[94] Yu, Q.; Jin, L.; Zhou, C., Ab initio study of electronic structures and absorption properties of pure and $\mathrm{Fe}^{3+}$ doped anatase $\mathrm{TiO}_{2}$. Sol. Energy Mater. Sol. Cells 2011, 95 (8), 2322-2326.

[95] Bessekhouad, Y.; Robert, D.; Weber, J. V., $\mathrm{Bi}_{2} \mathrm{~S}_{3} / \mathrm{TiO}_{2}$ and $\mathrm{CdS} / \mathrm{TiO}_{2}$ heterojunctions as an available configuration for photocatalytic degradation of organic pollutant. J. Photochem. Photobiol., A 2004, 163 (3), 569-580.

[96] Wu, L.; Yu, J. C.; Fu, X. Characterization and photocatalytic mechanism of nanosized $\mathrm{CdS}$ coupled $\mathrm{TiO}_{2}$ nanocrystals under visible light irradiation. J. Mol. Catal. A: Chem. 2006, 244 (1-2), 25-32.

[97] Li, D.; Haneda, H. Enhancement of photocatalytic activity of sprayed nitrogen-containing $\mathrm{ZnO}$ powders by coupling with metal oxides during the acetaldehyde decomposition. Chemosphere 2004, 54 (8), 1099-1110. 
[98] Sheng, G.; Li, J.; Wang, S.; Wang, X. Modification to promote visible-light catalytic activity of $\mathrm{TiO}_{2}$. Progress in Chemistry 2009 , 21 (12), 2492-2504.

[99] Walsh, A.; Yan, Y.; Huda, M. N.; Al-Jassim, M. M.; Wei, S. H. Band edge electronic structure of $\mathrm{BiVO}_{4}$ : Elucidating the role of the Bi s and V d orbitals. Chem. Mater. 2009, 21 (3), $547-551$

[100] Wang, H.; Baek, S.; Lee, J.; Lim, S. High photocatalytic activity of silver-loaded $\mathrm{ZnO}-\mathrm{SnO}_{2}$ coupled catalysts. Chem. Eng. J. 2009, 146 (3), 355-361.

[101] Yang, Y.; Zhong, H.; Tian, C., Photocatalytic mechanisms of modified titania under visible light. Res. Chem. Intermed. 37 (1), 91-102.

[102] Li, D.; Haneda, H. Synthesis of nitrogen-containing $\mathrm{ZnO}$ powders by spray pyrolysis and their visible-light photocatalysis in gasphase acetaldehyde decomposition. J. Photochem. Photobiol., A 2003, $155(1-3), 171-178$.

[103] Li, D.; Haneda, H.; Ohashi, N.; Hishita, S.; Yoshikawa, Y. Synthesis of nanosized nitrogen-containing $\mathrm{MOx}-\mathrm{ZnO}(\mathrm{M}=\mathrm{W}, \mathrm{V}$, $\mathrm{Fe}$ ) composite powders by spray pyrolysis and their visible-lightdriven photocatalysis in gas-phase acetaldehyde decomposition. Catal. Today 2004, 93-95, 895-901.

[104] Peng, F.; Cai, L.; Huang, L.; Yu, H.; Wang, H. Preparation of nitrogen-doped titanium dioxide with visible-light photocatalytic activity using a facile hydrothermal method. J. Phys. Chem. Solids 2008, 69 (7), 1657-1664.

[105] Shen, H.; Mi, L.; Xu, P.; Shen, W.; Wang, P. N. Visible-light photocatalysis of nitrogen-doped $\mathrm{TiO} 2$ nanoparticulate films prepared by low-energy ion implantation. Appl. Surf. Sci. 2007, 253 (17), 7024-7028.

[106] Peng, F.; Cai, L.; Yu, H.; Wang, H.; Yang, J. Synthesis and characterization of substitutional and interstitial nitrogen-doped titanium dioxides with visible light photocatalytic activity. J. Solid State Chem. 2008, 181 (1), 130-136.

[107] Nakamura, I.; Negishi, N.; Kutsuna, S.; Ihara, T.; Sugihara, S.; Takeuchi, K. Role of oxygen vacancy in the plasma-treated TiO2 photocatalyst with visible light activity for NO removal. J. Mol. Catal. A: Chem. 2000, 161 (1-2), 205-212.

[108] Ihara, T.; Miyoshi, M.; Iriyama, Y.; Matsumoto, O.; Sugihara, S. Visible-light-active titanium oxide photocatalyst realized by an oxygen-deficient structure and by nitrogen doping. Appl. Catal., B 2003, 42 (4), 403-409.

[109] Bloh, J. Z.; Dillert, R.; Bahnemann, D. W., Transition metalmodified zinc oxides for UV and visible light photocatalysis. Environ. Sci. Pollut. Res. 2012, 19, 3688-3695.

[110] Lv, T.; Pan, L.; Liu, X.; Sun, Z., Visible-light photocatalytic degradation of methyl orange by CdS-TiO 2-Au composites synthesized via microwave-assisted reaction. Electrochim. Acta 2012, 83, 216-220.

[111] Vereb, G.; Manczinger, L.; Oszko, A.; Sienkiewicz, A.; Forro, L.; Mogyorosi, K.; Dombi, A.; Hernadi, K., Highly efficient bacteria inactivation and phenol degradation by visible light irradiated iodine doped $\mathrm{TiO}_{2}$. Appl. Catal., B 2013, 129, 194-201.

[112] Wang, Q.; Yang, X.; Liu, D.; Chi, L.; Hou, J., Ag and CdS nanoparticles co-sensitized $\mathrm{TiO}_{2}$ nanotubes for enhancing visible photoelectrochemical performance. Electrochim. Acta 2012, 83, 140-145.

[113] Hossain, M. K.; Ghosh, S. C.; Boontongkong, Y.; Thanachayanont, C.; Dutta, J. Growth of Zinc Oxide nanowires and nanobelts for gas sensing applications. Journal of Metastable and Nanocrystalline Materials 2005, 23, 27-30.

[114] Choo, K. H.; Tao, R.; Kim, M. J. Use of a photocatalytic membrane reactor for the removal of natural organic matter in water: Effect of photoinduced desorption and ferrihydrite adsorption. J. Membr. Sci. 2008, 322 (2), 368-374.

[115] Zhang, X.; Du, A. J.; Lee, P.; Sun, D. D.; Leckie, J. O. $\mathrm{TiO}_{2}$ nanowire membrane for concurrent filtration and photocatalytic oxidation of humic acid in water. Journal of Membrane Science 2008, 313 (1-2), 44-51.

[116] Mozia, S. Photocatalytic membrane reactors (PMRs) in water and wastewater treatment. A review. Sep. Purif. Technol. 73 (2), 71-91.
[117] Molinari, R.; Grande, C.; Drioli, E.; Palmisano, L.; Schiavello, M. Photocataytic membrane reactors for degradation of organic pollutants in water. Catal. Today 2001, 67 (1-3), 273-279.

[118] Choi, H.; Stathatos, E.; Dionysiou, D. D. Sol-gel preparation of mesoporous photocatalytic $\mathrm{TiO}_{2}$ films and $\mathrm{TiO}_{2} / \mathrm{Al}_{2} \mathrm{O}_{3}$ composite membranes for environmental applications. Appl. Catal. B: Environmental 2006, 63 (1-2), 60-67.

[119] Horng, R. Y.; Huang, C.; Chang, M. C.; Shao, H.; Shiau, B. L.; Hu, Y. J. Application of $\mathrm{TiO}_{2}$ photocatalytic oxidation and non-woven membrane filtration hybrid system for degradation of 4chlorophenol. Desalination 2009, 245 (1-3), 169-182.

[120] Mozia, S.; Tomaszewska, M.; Morawski, A. W. A new photocatalytic membrane reactor (PMR) for removal of azo-dye Acid Red 18 from water. Applied Catalysis B: Environmental 2005, 59 (1-2), 131-137.

[121] Liu, L.; Chen, F.; Yang, F., Stable photocatalytic activity of immobilized $\mathrm{Fe}_{0} / \mathrm{TiO}_{2} / \mathrm{ACF}$ on composite membrane in degradation of 2,4-dichlorophenol. Sep. Purif. Technol. 2009, 70 (2), 173-178.

[122] Wang, W. Y.; Irawan, A.; Ku, Y. Photocatalytic degradation of Acid Red 4 using a titanium dioxide membrane supported on a porous ceramic tube. Water Res. 2008, 42 (19), 4725-4732.

[123] Chen, S.; Chen, Q.; Zheng, X.; Chen, X.; Chen, Z. Preparation of sandwich bipolar membrane and its photocatalytic properties. Chinese J. Appl. Chem. 2010, 27(11), 1301-1305.

[124] Chen, S. L.; Wang, A. J.; Hu, C. T.; Dai, C.; Benziger, J. B. Enhanced photocatalytic performance of nanocrystalline $\mathrm{TiO}_{2}$ membrane by both slow photons and stop-band reflection of photonic crystals. AlChE J. 2012, 58(2), 568-572.

[125] Choi, W. Y.; Chung, J.; Cho, C. H.; Kim, J. O. Fabrication and photocatalytic activity of a novel nanostructured $\mathrm{TiO}_{2}$ metal membrane. Desalination 2011, 297, 359-366.

[126] Linh, N. T. B.; Lee, K. H.; Lee, B. T. Fabrication of photocatalytic $\mathrm{PVA}^{-\mathrm{TiO}_{2}}$ nano-fibrous hybrid membrane using the electrospinning method. J. Mater. Sci. 2011, 46 (17), 5615-5620.

[127] Oh, S. L.; Choi, K. H.; Im, J. E.; Wang, K. K.; Yaung, H. Y.; Kim, K.; Kim, Y. R. Fabrication of mesoporous titania membrane of dual-pore system and its photocatalytic activity and dye-sensitized solar cell performance. Nanotechnology 2011, 22 (27), 275309.

[128] Park, S. Y.; Lee, H. U.; Ahn, K.; Kim, J. P.; Jin, J. S.; Lee, J.; Jeong, S. Y.; Cho, C. R. Enhanced photocatalytic activity of $\mathrm{TiO}_{2-}$ incorporated nanofiber membrane by oxygen plasma treatment. Thin Solid Films 2011, 519(20), 6899-6902.

[129] Ding, X.; Zhou, S.; Jiang, L.; Yang, H. Preparation, photocatalytic activity and mechanism of nano-Titania/Nafion hybrid membrane. J. Sol-Gel Sci. Technol. 2011, 58 (1), 345-354.

[130] Lombardi, M.; Palmero, P.; Sangermano, M.; Varesano, A. Electrospun polyamide- 6 membranes containing titanium dioxide as photocatalyst. Polym. Int. 2011, 60 (2), 234-239.

[131] Neubert, S.; Pliszka, D.; Thavasi, V.; Wintermantel, E.; Ramakrishna, S. Conductive electrospun PANi-PEO/TiO ${ }_{2}$ fibrous membrane for photo catalysis. Mater. Sci. Engineer. B 2011, 176 (8), 640-646.

[132] Xiao, Y. T.; Xu, S. S.; Du, Y. C.; Shiang, F. Q. Progress of novel $\mathrm{TiO}_{2}$ photocatalytic separation membrane. Wuji Cailiao Xuebao/J. Inorg. Mater. 2011, 26 (4), 337-346.

[133] Bai, H.; liu, Z.; Sun, D. D., Hierarchical ZnO nanostructured membrane for multifunctional environmental applications. Colloids Surf., A 2012, 410, 11-17.

[134] Myint, M. T. Z.; Dutta, J., Zinc oxide microrods coated superhydrophobic cotton fabric. In Thailand Textile Symposium 2010 Miracle Grand, bangkok, Thailand, 2010.

[135] Promnimit, S.; Cavelius, C.; Mathur, S.; Dutta, J. Growth of gold/zinc sulphide multilayer films using layer-by-layer assembly of colloidal nanoparticles. Physica E 2008, 41 (2), 285-291.

[136] Promnimit, S.; Jafri, S. H. M.; Sweatman, D.; Dutta, J. Conduction properties of layer-by-layer self-assembled multilayer nanoparticulate structures. J. Nanoelectron. Optoelectron. 2008, 3 (2), 184-189.

[137] Bhadra, P.; Mitra, M. K.; Das, G. C.; Dey, R.; Mukherjee, S. Interaction of chitosan capped $\mathrm{ZnO}$ nanorods with Escherichia coli. Mater. Sci. Engineer., 2011, C 31 (5), 929-937. 
[138] Eskandari, M.; Haghighi, N.; Ahmadi, V.; Haghighi, F.; Mohammadi, S. R. Growth and investigation of antifungal properties of $\mathrm{ZnO}$ nanorod arrays on the glass. Physica B 2011, 406 (1), 112-114.

[139] Ma, X.-Y.; Zhang, W.-D., Effects of flower-like ZnO nanowhiskers on the mechanical, thermal and antibacterial properties of waterborne polyurethane. Polym. Degrad. Stab. 2009, 94 (7), 1103-1109.

[140] Tam, K. H.; Djurisic, A. B.; Chan, C. M. N.; Xi, Y. Y.; Tse, C. W.; Leung, Y. H.; Chan, W. K.; Leung, F. C. C.; Au, D. W. T. Antibacterial activity of $\mathrm{ZnO}$ nanorods prepared by a hydrothermal method. Thin Solid Films 2008, 516 (18), 6167-6174.
[141] Jackson, M. J.; Giugliano, R.; Giugliano, L. G.; Oliveira, E. F.; Shrimpton, R.; Swainbank, I. G. Stable isotope metabolic studies of zinc nutrition in slum-dwelling lactating women in the Amazon valley. Br. J. Nutr. 1988, 59 (2), 193-203.

[142] Cavdar, A. O.; Arcasoy, A.; Cin, S.; Gumus, H. Zinc deficiency in geophagia in Turkish children and response to treatment with zinc sulphate. Haematologica 1980, 65 (3), 403-408.

[143] Baruah, S.; Jaisai, M.; Dutta, J., Development of a visible light active photocatalytic portable water purification unit using $\mathrm{ZnO}$ nanorods. Catal. Sci. Technol. 2012, 2, 918-921. 